\title{
Book Review: The Power of Vulnerability. Mobilising Affect in Feminist, Queer and Anti-Racist Media Cultures edited by Anu Koivunen, Katariina Kyrölä and Ingrid Ryberg, Manchester University Press, 2018, 246 pages. ISBN: 978-1-5261-3309-0
}

\author{
Verena Kettner \\ University of Vienna, AT \\ verena.kettner@univie.ac.at
}

Keywords: vulnerability; visibility; (queer)feminist; anti-racist; media-culture

The anthology 'The Power of Vulnerability. Mobilising Affect in Feminist, Queer and Anti-Racist Media Cultures', edited by Anu Koivunen, Katariina Kyrölä and Ingrid Ryberg, is a very diverse and theoretically loaded contribution to current (queer-)feminist and anti-racist debates about vulnerability in medial contexts.

The issue consists, together with the editors' introduction, of three sections with different content focus: (1) vulnerability in current feminist debates, such as trigger warnings or \#MeToo, (2) the positive and negative effects of vulnerability's visibility, and (3) vulnerability in cultural political contexts. All the contributions have an affect theoretical, (queer-)feminist and partly anti-racist perspective on vulnerability, showing that vulnerability can be more than weakness and disadvantage in political cultures. Rather, the editors as well as the authors of the contributions frame vulnerability on the one hand as a powerful starting point for mobilisation, communication, and policymaking and on the other hand as a tool to uncover and challenge patriarchal and racist power relations. Vulnerability in this anthology is still connected with injury, suffering, and hurt, but it is also seen as something with productive and empowering potentials.

In the introduction, the editors trace the current debates about vulnerability in relation to questions that emerged in movements like \#MeToo and \#BlackLivesMatter: To what extent can representations of injury and vulnerability produce empowerment and to what extent can they contribute to endanger and hurt the persons concerned even more? How can we understand this new 'language of vulnerability' (p. 4) in (queer-)feminist and anti-racist media cultures? How do our various understandings of vulnerability mobilise different affects and what are the effects thereof? In their short description of theoretical legacies of vulnerability as a concept, they especially emphasize Judith Butler's perception of vulnerability always related to power, norms and recognition. Although Butler understands vulnerability as a 
general condition of human life in this conception, she also recognizes that the distribution of vulnerability between bodies and around the globe is radically different and based on multiple power relations like racism and (hetero-)sexism. It is recognition that for Butler shifts vulnerability from universal co-dependency towards political mobilisation (p. 11). The centrality of recognition in relation to vulnerability also runs through the rest of the anthology and its considerations of vulnerability in political language.

The contributions of Katariina Kyrölä, Jack Halberstam, and Sara Ahmed deal with vulnerability in recent trigger warning debates in different contexts and the empowering as well as repressive potentials of the different handlings of vulnerability. Kyrölä's article aims to examine the discourses around online debates about trigger warnings and how they mobilise varying understandings of vulnerability. She identifies feminist pro- as well as anti-triggerwarning arguments and anti-feminist anti-trigger-warnings discourses. While not following the last ones, she examines how the feminist pro- and anti-trigger-warning arguments are producing inclusion and exclusion from different points of view. Halberstam's contribution in turn illuminates the risk of trigger warnings on campus being paternalistic and an unnecessary protection of students based on the idea that they are a monochromatic group of spoiled and fragile children. Fragility also is a key topic in Ahmed's article that is re-printed from her blog 'Feminist Killjoy' and engaging with the politics of hurt. Drawing from Audre Lorde, Ahmed conceives feminism as a practice of remembering and stresses the importance of the ability to feel hurt. Instead of being protected from what hurts, we need to notice what causes the pain 'if we are to produce critical understandings of how violence, as a relation of force and harm, is directed toward some bodies and not others' (p. 61). Ahmed introduces the concept of feeling structures and the figure of the too-easily-hurt gender studies student to show the hierarchical power relations that can be hidden beyond trigger warnings and suggests to ask for more instead for less: more complexity and more creative responses to hurting and unfinished histories.

The next section, with contributions from Ylva Habel, Laura Horak, Johanna Gondouin/Suruchi Thapar-Björkert/Ingrid Ryberg, and Susanna Paasonen, is concerned with vulnerability as a discourse reproducing discrimination. As Ylva Habel shows in her examination of the discourses around the racialized, stereotype figure 'Little Pink' in the kids' movie 'Little Pink and the Motley Crew', vulnerability becomes a form of affective currency for white fragility. Instead of the PoC concerned by the anti-black racism that is displayed in the movie, their white discussion partners who find the critique too radical and who didn't mean to hurt anybody, are framed as the hurt ones in the conflict. White, straight, cis men can also become vulnerable subjects through their representation, as Susanna Paasonen states in her dealing with the intermeshing of privilege, vulnerability and desirability in the novel 'Fifty Shades of Grey'. The representation of the novel's male main character, Christian Grey, as a from childhood trauma deeply wounded subject, frames vulnerability as individual trauma and erases the political background of the concept in Butler's sense. Additionally, this conception of vulnerability also consolidates toxic and violent gender hierarchies affectively, as it claims that the only one able to save Christian from his suffering, which legitimates his abusive behaviour, is his girlfriend Anna through her unconditional and of course unpaid labour of love. Johanna Gondouin, Suruchi Thapar-Björkert, and Ingrid Ryberg also engage with the erasure of precariousness and vulnerability as conditions 'depending on one's positionality within a multi-layered field of power (Butler 2014: 5)' (p. 122). They show that the emphasis on the reproductive vulnerability of the white parents using surrogacy in the movie Top of the Lake: China Girl makes the precariousness of the Thai surrogate's living conditions invisible. Interestingly, not only the whitewashing of vulnerability of non-white bodies in structurally 
racist societies is elaborated in the article, but also the legitimation of white saviourism through exactly this same vulnerability. What may seem contradictory at first sight, is rather just different effects of mobilising affects in order to disguise structural racism. By dealing with the translatina movies The Salt Mines and Wildness, Laura Horak considers how to not reproduce this structural racism and hetero-sexism. She reflects about how documentary filmmakers can encounter the most vulnerable and centre their experiences without othering or instrumentalizing them or increasing their vulnerability. She points to the importance of media visibility for queer strategies to constitute identities and kinship on the one hand, but also to the dangers of queer visibility, like transphobic hate crimes, on the other hand.

In the last section of the anthology, the focus lies on examinations of the handling of vulnerability in Swedish (queer-)feminist and anti-racist media cultures. Mara Lee Gerdén explores the question of affective privilege - which emotions can be articulated by whom - based on an examination of Fusion Programme launched by the Swedish Film Institute to promote diversity. She shows that through representing the black body as invulnerable, the expectation of 'overcoming' racist expectations and at some point 'feeling good' again becomes legitimized and histories as well as the presence of pain are neglected. Dagmar Brunow highlights in her article how film archives in Sweden can contribute to a recognition of LGBTQ-related contents on the one hand and the ambivalences of visibility on the other hand, as it exposes queer lives and stories to the public and thus makes them even more vulnerable. Ingrid Ryberg's contribution deals with the role that the lesbian movies Eva and Maria and The Woman in Your Life Is You played in Swedish policymaking and creating an ambiguous sexual citizenship in the so-called gay-liberation era in the 1970s. Ryberg argues that the representation of homosexuals as victims of discrimination and prejudice was the basis for its decriminalisation, as shown in Eva in Maria representing the women as innocent and victimized. Hardly recognized, however, was the vulnerability of (queer) women to patriarchal oppression on a structural level, shown by The Woman in Your Life Is You, which was the less popular movie of the two. The last contribution of the anthology by Anu Koivunen presents an affective historiography of how Sweden affectively re-framed the AIDS epidemic in order to represent itself as the caring nation it is seen as nowadays. The TV drama Don't Ever Wipe Tears Without Gloves, which was broadcast in Sweden in 2013, enabled a 're-enactment of the original trauma, functioning as a mode of affective historiography' (p. 224) that re-wrote the gay and the national narratives of the AIDS epidemic through one another. Re-imagining and representing the trauma of the AIDS epidemic as a national one contributed to reinventing the caring Swedish nation.

With all its diverse and inspiring contributions, the anthology accelerates a very current and important feminist discourse about the possibilities and risks of vulnerability and (in)visibility. It illuminates the instrumentalization of vulnerability from various angles and therefore manages to uncover and critique racist and patriarchal hierarchical power relations not only in the (Swedish) mainstream society, but even within feminist discourses and (media) cultures. The manifold analyses of vulnerability's affective implications obtain a differentiated perspective on the emancipatory potentials of vulnerability as a feminist political tool as well as its risks of reproducing white, cis-gendered, or heterosexist power hierarchies. The diversity and different concentrations of the contributions are very important aspects of the anthology, and it is very refreshing to read more than only one token article dealing with vulnerability regarding PoC and transgender identities. It would have been even better, if the intersectional perspective was followed consequently throughout the whole anthology. Although this is a difficulty that not only this book has to deal with, but the whole feminist academia. 


\section{Competing Interests}

The author has no competing interests to declare.

\section{Reference}

Butler, Judith. 2014. "Vulnerability and resistance revisited". Presentation at Trinity College. Dublin, February.

How to cite this article: Kettner, Verena. 2020. "Book Review: The Power of Vulnerability. Mobilising Affect in Feminist, Queer and Anti-Racist Media Cultures edited by Anu Koivunen, Katariina Kyrölä and Ingrid Ryberg, Manchester University Press, 2018, 246 pages. ISBN: 978-1-5261-3309-0." Redescriptions: Political Thought, Conceptual History and Feminist Theory 23(2), pp. 173-176. DOl: https://doi.org/10.33134/rds.343

\section{Submitted: 27 October 2020 Accepted: 28 October 2020 Published: 15 December 2020}

Copyright: (c) 2020 The Author(s). This is an open-access article distributed under the terms of the Creative Commons Attribution 4.0 International License (CC-BY 4.0), which permits unrestricted use, distribution, and reproduction in any medium, provided the original author and source are credited. See http://creativecommons.org/licenses/by/4.0/. 